\title{
Poster: An Experimental Study of Micropore Defects in MFI Membranes
}

\author{
Danil Korelskiy, Han Zhou, Johanne Mouzon and Jonas Hedlund \\ Chemical Technology, Luleå University of Technology, SE-971 87 Luleå, Sweden \\ E-mail: danil.korelskiy@ltu.se
}

In earlier works, we demonstrated that permporometry was a reliable and effective tool for characterization of mesopore [1] and micropore [2] defects. The results could be validated against separation data, but it was only possible to directly observe the mesopore defects by scanning electron microscopy (SEM) due to the limited resolution of the instrument.

In this work, two types of ultra-thin $(\sim 0.5 \mu \mathrm{m})$ MFI membranes, prepared using $\mathrm{OH}^{-}[3]$ and $\mathrm{F}^{-}$[4] as mineralizing agents respectively, with a notably different amount of micropore defects were minutely examined by permporometry. The results were verified by SEM data recorded using a state-of-the-art FEI Magellan 400 XHR instrument, permeation data using mesitylene (TMB), a probe molecule with a kinetic diameter of $0.75 \mathrm{~nm}$, hence, permeating only defects, and nitrogen adsorption data recorded for as-synthesized MFI crystals.

According to the permporometry data, the total amount of micropore defects in fluoride membranes was $\sim 0.3 \%$ of the total membrane area, which is nearly two times lower than that $(0.6 \%)$ in hydroxide membranes. Figure 1 shows cross section HR-SEM images of hydroxide and fluoride MFI membranes. A significantly lower amount of micropore defects is observed in the fluoride membrane compared to the hydroxide membrane, in good agreement with the permporometry data. The permporometry results were also consistent with the permeation data, i.e., a proportionally higher permeance of TMB was observed for hydroxide membranes.

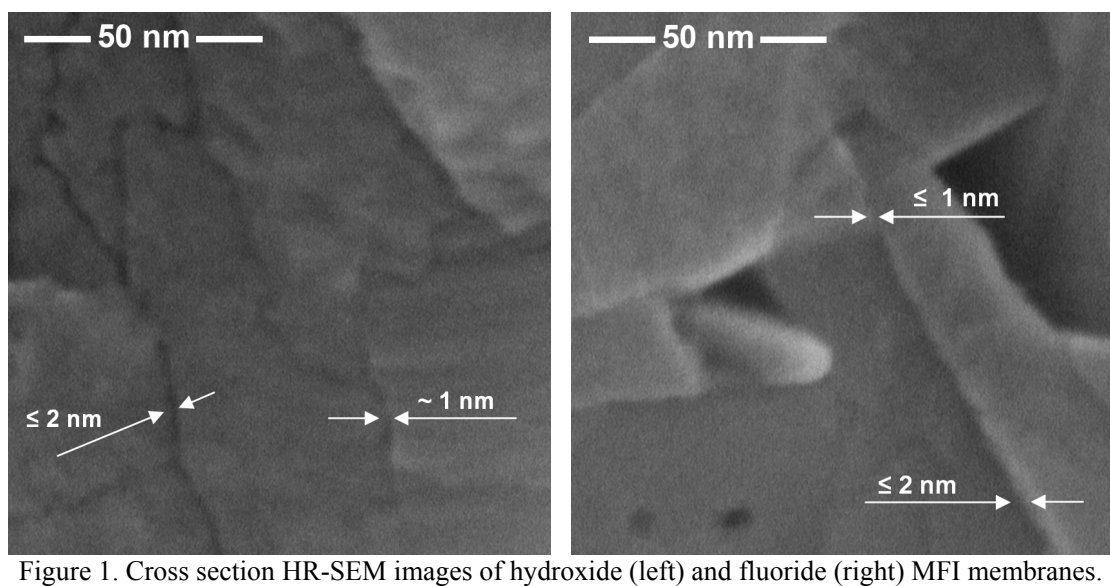

\section{References:}

[1] J. Hedlund, D. Korelskiy, L. Sandström, J. Lindmark, J. Membr. Sc., 2009, 345, 276-287.

[2] D. Korelskiy, M. Grahn, J. Mouzon, J. Hedlund, J. Membr. Sc., 2012, 417-418, 183-192.

[3] J. Hedlund, J. Sterte et. al., Micropor. Mesopor. Mater., 2002, 52, 179-189.

[4] H. Zhou, D. Korelskiy, J. Hedlund, To be submitted to Micropor. Mesopor. Mater. (IZMM6 issue). 